\title{
IDENTIFIKASI WASTE DENGAN MENGGUNAKAN METODE VALUE STREAM MAPPING PADA INDUSTRI PERUMAHAN
}

\author{
Yassyir Maulana \\ Program Studi Teknik Industri, Fakultas Teknik, Universitas Islam Kalimantan MAB \\ Jalan Adhyaksa No.2 Kayutangi Banjarmasin, Kalimantan Selatan \\ Email : yasir.industri@gmail.com
}

\begin{abstract}
Abstrak- Value Stream Mapping adalah suatu metode pemetaan aliran produksi dan aliran informasi untuk memproduksikan satu produk atau satu family produk, yang tidak hanya pada masingmasing area kerja, tetapi pada tingkat total produksi serta mengidentifikasi kegiatan yang termasuk value added dan non value added. Tujuan dari penelitian ini adalah untuk meningkatkan produktivitas dengan mengidentifikasi waste yang terjadi pada proses produksi dan untuk memberikan rekomendasi perbaikan pada proses produksi untuk mengurangi waste. Hasil penelitian menyatakan bahwa waste yang terjadi pada proses pembuatan rumah tipe 36 di perumahan Griya Anisah Permai yaitu terdapat pada persediaan bahan, baku, waktu menunggu dan Gerakan yang tidak perlu. Untuk mengurangi transportasi pada proses produksi sebaiknya pengantaran bahan baku (material) jangan hanya ke Gudang bahan baku tetapi bisa langsung ke lokasi tempat kerja berlangsung.
\end{abstract}

Kata Kunci : Value Stream Mapping, Waste, Value Added, Non Value Added.

\section{PENDAhuluan}

Proses produksi merupakan kegiatan untuk menciptakan atau menambah kegunaan suatu barang atau jasa dengan menggunakan faktor-faktor yang ada seperti tenaga kerja, mesin, bahan baku dan dana agar lebih bermanfaat bagi kebutuhan manusia. Jenis Proses produksi terdiri dari beberapa antara lain: a) Jenis proses produksi ditinjau dari segi wujud proses produksi, yang meliputi: proses produksi kimiawi, proses produksi perubahan bentuk, proses Proses produksi assembling, Proses produksi transportasi, Proses produksi penciptaan jasa administrasi; b) Jenis proses produksi ditinjau dari segi arus proses produksi, meliputi: Proses produksi terus menerus (Continous processes) dan Proses produksi terputusputus (intermitten processes); dan c) Jenis proses produksi ditinjau dari segi keutamaan proses produksi, meliputi: Proses produksi utama dan proses produksi bukan utama [1].

Peningkatan kualitas pada proses produksi merupakan hal yang sangat diperlukan suatu industri. Tetapi hal itu tidak akan pernah terjadi jika masih terdapat waste/pemborosan di dalam proses produksi tersebut. Untuk itu salah satu cara untuk meningkatkan kualitas pada proses produksi dengan mengurangi waste/pemborosan tersebut. Salah satu metode yang dapat digunakan dalam usaha mengeliminasi waste adalah Lean Manufacturing. Menurut Gasperz dalam [2] menyatakan bahwa Lean adalah suatu upaya terus-menerus untuk menghilangkan pemborosan (waste) dan meningkatkan nilai tambah (value added) produk (barang dan/atau jasa) agar memberikan nilai kepada pelanggan (customer value). Menurut Taiichi Ohno dalam [3], ada 7 (tujuh) tipe waste yang biasa ditemukan dalam suatu perusahaan. Ketujuh tipe waste tersebut yaitu: Transportation, Inventories, Motion, Waiting/Delay, Over Production, Over Processing, dan defect.

Salah satu tool lean manufacturing yang untuk mengidentifikasi waste dalam proses produksi adalah Value Stream Mapping (VSM). Value Stream Mapping (VSM) merupakan Process Mapping yang menunjukkan secara detail aliran material, aliran informasi, parameter operational lead time, yield, uptime, frekuensi pengiriman, jumlah manpower, ukuran batch, jumlah inventori, setup time, process time, efisiensi proses secara keseluruhan, dll. [3].

Dari penelitian di atas dapat bahwa Value Stream Mapping (VSM) sangat berguna untuk mengidentifikasi waste dalam sebuah lini proses produksi. Oleh karena itu penelitian ini mencoba mengangkat judul penelitian "Identifikasi Waste Pada Produksi Industri Mebel Dengan Value Stream Mapping".

\section{A. Lean Manufacturing}

Lean Manufacturing adalah filosofi yang dimulai di manufaktur Jepang, untuk menghilangkan semua limbah dari prosesnya sambil mengejar peningkatan kualitas dalam menghasilkan produk jadi. Inti dari penerapan sistem lean manufacturing adalah dimana sistem ini berfokus pada kegiatan mengidentifikasi dan menghilangkan segala bentuk pemborosan sehingga membentuk sebuah sistem manufaktur yang ramping dan efisien (Satao, et al., 2012) dalam [4].

Lean dapat didefinisikan sebagai suatu upaya terus menerus untuk menghilangkan pemborosan (waste) dan meningkatkan nilai tambah (value added) produk agar memberi nilai kepada pelanggan (customer value). Dalam implementasinya, konsep Lean didasarkan pada empat prinsip, yaitu [3]:

1. Specify Value

Mengidentifikasi nilai produk dari sudut pandang pelanggan dan menetapkan spesifikasi nilai produk yang diinginkan oleh pelanggan secara tepat.

2. Value Stream Analysis

Mengidentifikasi tahapan-tahapan yang diperlukan, mulai dari proses desain, pemesanan dan pembuatan produk berdasarkan keseluruhan aliran nilai untuk menemukan pemborosan yang tidak memberi nilai tambah.

3. Flow

Setiap kegiatan yang memberi nilai tambah diatur agar mengalir tanpa hambatan dari satu proses ke proses yang lain.

4. Pull System

Mengorganisir agar aliran material, informasi maupun produk dapat berjalan dengan lancar dan efisien sepanjang 
aliran proses menggunakan pull system. Pull system merupakan sistem baru yang menggunakan tarikan permintaan sebagai dasar melakukan produksi.

Menurut Gaspersz (2007: 9) dalam [5], lean manufacturing merupakan suatu sistem produksi yang menggunakan energi dan pemborosan yang sangat sedikit untuk memenuhi apa yang menjadi keinginan konsumen dengan tepat. Tujuan dari lean manufacturing adalah mengeliminasi pemborosan (non value adding activity) dari suatu proses sehingga aktivitas-aktivitas sepanjang value stream mampu menghasilkan value adding.

\section{B. Waste/Pemborosan}

Menurut Suhartono (2007: 13-14) dalam [5], di dalam Toyota Production System (TPS) terdapat tujuh waste dalam proses produksi yaitu sebagai berikut:

1. Overproduction, yaitu pemborosan yang disebabkan produksi yang berlebihan, maksudnya adalah memproduksi produk yang melebihi yang dibutuhkan atau memproduksi lebih awal dari jadwal yang sudah buat.

2. Waiting, yaitu pemborosan karena menunggu untuk proses berikutnya. Waiting merupakan selang waktu ketika operator tidak menggunakan waktu untuk melakukan value adding activity dikarenakan menunggu aliran produk dari proses sebelumnya (upstream).

3. Transportation, transportasi merupakan kegiatan yang penting akan tetapi tidak menambah nilai pada suatu produk. Transportasi merupakan proses memindahkan material atau work in process (WIP) dari satu stasiun kerja ke stasiun kerja yang lainnya, baik menggunakan forklift maupun conveyor.

4. Excess processing, terjadi ketika metode kerja atau urutan kerja (proses) yang digunakan dirasa kurang baik dan fleksibel. Hal ini juga dapat terjadi ketika proses yang ada belum standar sehingga kemungkinan produk yang rusak akan tinggi. Adanya variasi metode yang dikerjakan operator.

5. Inventories, adalah persediaan yang kurang perlu. Maksudnya adalah persediaan material yang terlalu banyak, work in process yang terlalu banyak antara proses satu dengan yang lainnya sehingga membutuhkan ruang yang banyak untuk menyimpannya, kemungkinan pemborosan ini adalah buffer yang sangat tinggi.

6. Motion, adalah aktivitas/pergerakan yang kurang perlu yang dilakukan operator yang tidak menambah nilai dan memperlambat proses sehingga lead time menjadi lama.

7. Defects, adalah produk yang rusak atau tidak sesuai dengan spesifikasi. Hal ini akan menyebabkan proses rework yang kurang efektif, tingginya komplain dari konsumen, serta inspeksi level yang sangat tinggi.

\section{Value Stream Mapping (VSM)}

Value Stream Mapping (VSM) adalah suatu konsep dari lean manufacturing yang menunjukkan suatu gambar dari seluruh kegiatan atau aktivitas yang dilakukan oleh sebuah perusahaan [6]. VSM mencakup pemasok bahan baku, manufaktur dan perakitan produk, serta jaringan pendistribusian kepada pengguna barang tersebut [4].

Value Stream Mapping digunakan untuk menggambarkan sistem produksi (mulai dari memesan bahan baku sampai produk jadi siap distribusi) beserta aliran nilai (value stream) yang terdapat pada perusahaan, sehingga nantinya diperoleh gambaran mengenai aliran informasi dan aliran fisik dari sistem yang ada, mengidentifikasi lokasi terjadinya waste, serta menggambarkan lead time yang dibutuhkan berdasar dari masing-masing karakteristik proses yang terjadi [7].

Menurut (Fontana \& Gaspersz, 2011) dalam [4], Value Stream mapping memiliki kelebihan yaitu cepat dan mudah dalam pembuatan, tidak harus menggunakan software komputer khusus, mudah dipahami dan meningkatkan pemahaman terhadap sistem produksi yang sedang berjalan serta memberikan gambaran aliran perintah informasi produksi. Sedangkan kekurangan dari Value Stream Mapping adalah aliran material hanya bias untuk satu produk atau satu tipe produk yang sama pada satu VSM untuk dianalisis dan VSM berbentuk statis dan terlalu menyederhanakan masalah yang ada pada lantai produksi [8].

Terdapat 2 kondisi pemetaan pada perusahaan yang perlu dilakukan menurut (Vinodh, et al., 2015) dalam [4], yaitu current state map (kondisi awal) dan future state map (kondisi di masa depan). Current state map yaitu pandangan dasar dari proses yang ada di mana semua proses dalam produksi diukur, serta menjadi representasi semua entitas dan operasi dalam value chain. Future state map mewakili visi bagaimana melihat kondisi value chain pada satu titik di masa depan setelah perbaikan dilakukan. Perhatiannya terfokus pada pemetaan dengan pandangan proses produksi lebih efisien dan bebas dari waste sepanjang aliran value stream.

Dalam pembuatan VSM langkah-langkah yang harus dilalui, yaitu [3]:

1. Menentukan produk atau keluarga produk.

2. Membuat peta sekarang (current state map).

3. Membuat peta masa depan (future state map).

4. Merancang rencana perbaikan.

Berikut adalah contoh peta VMS (Value Stream Mapping). 


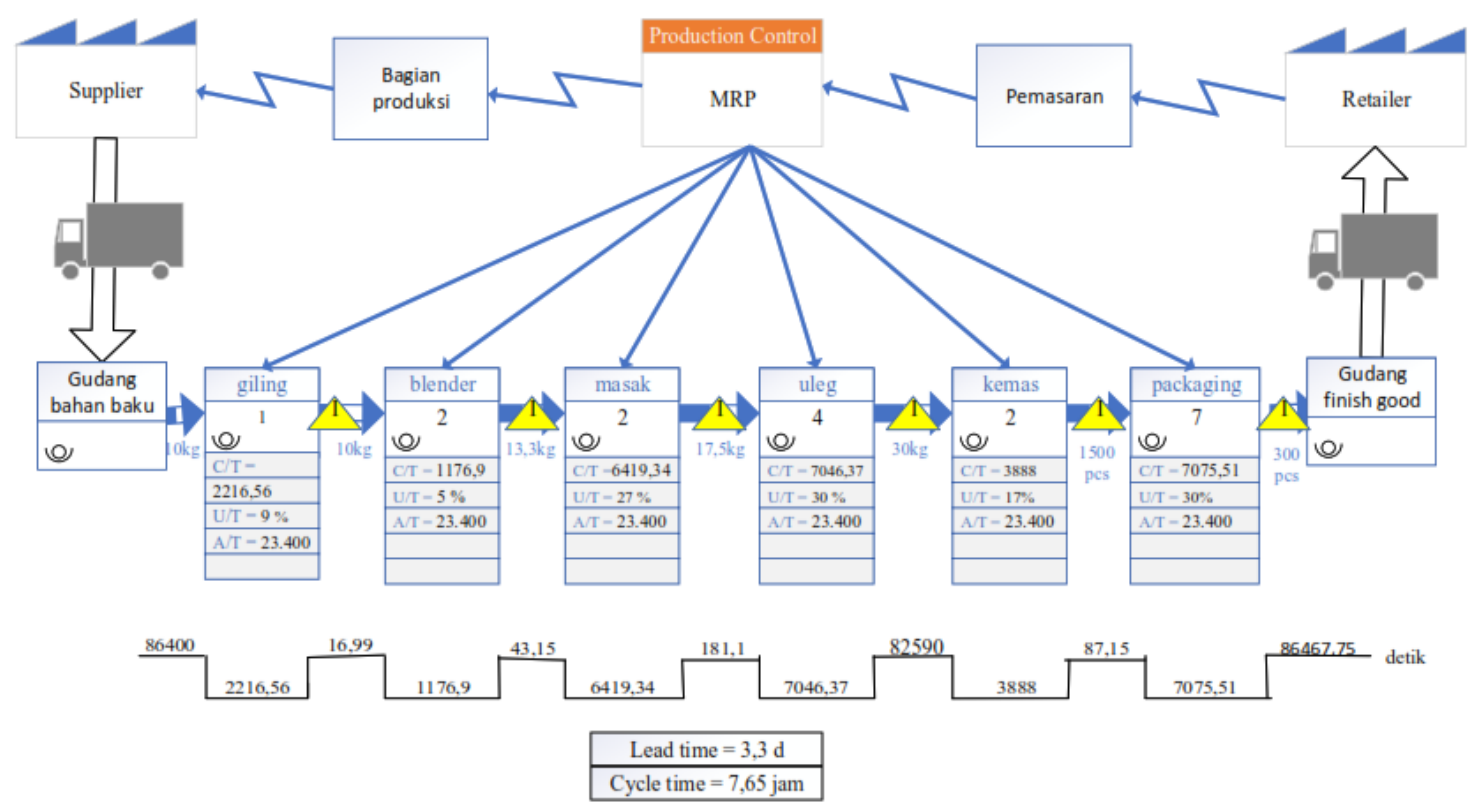

Gambar 1. Peta Value Stream Mapping

\section{Process Activity Mapping}

Process activity mapping (PAM) digunakan untuk mengetahui segala aktivitas-aktivitas yang berlangsung selama proses produksi kemudian mengklasifikasi aktivitas tersebut berdasarkan jenis waste nya. Tool ini bertujuan untuk menghilangkan aktivitas yang tidak diperlukan, mengidentifikasi apakah suatu proses dapat lebih diefisienkan lagi, serta mencari perbaikan yang dapat mengurangi pemborosan [10].

Process Active Mapping ini memiliki 5 langkah yang diperlukan [11] :

- Mempelajari aliran proses.

- Mengidentifikas pemborosan.

- Mempertimbangkan kemungkinan penataan ulang pola aliran termasuk layout dan penataan ulang.

- Mempertimbangkan apakah semua aktivitas yang dilakukan diperlukan atau tidak.

- Mempertimbangkan dampak yang terjadi bila ada aktivitas yang yang tidak diperlukan itu ditiadakan.

\section{METODE PENELITIAN}

1. Tahap Identifikasi dan Penelitian Awal

Pada tahap ini terdiri dari peninjauan perusahaan, identifikasi dan perumusan permasalahan kemudian penetapan tujuan penelitian, studi literatur, dan yang terakhir survey lapangan.

2. Tahap pengumbulan data

Pada tahap ini data primer dan data sekunder dikumpulkan. Data primer berupa informasi jenis waste, waktu proses operasi, waktu aktivitas operasi. Sedangkan data sekunder berupa aliran material, aliran informasi produksi, aktivitas operator, layout perusahaan, produk defect, permintaan order, dan inventory.
3. Tahap Pengolahan Data

Tahap ini melakukan pengolahan data dengan menggambarkan peta VMS (Value Stream Mapping).

4. Tahap Analisis dan Pembahasan

Tahap ini dilakukan analisis perbaikan serta pembahasan dari hasil pengolahan data.

5. Tahap Kesimpulan dan Saran

Pada tahap ini diambil kesimpulan berdasarkan analisis dan pembahasan yang telah dilakukan.

\section{HASIL DAN PEMBAHASAN}

\section{A. Proses Produksi Rumah Tipe 36}

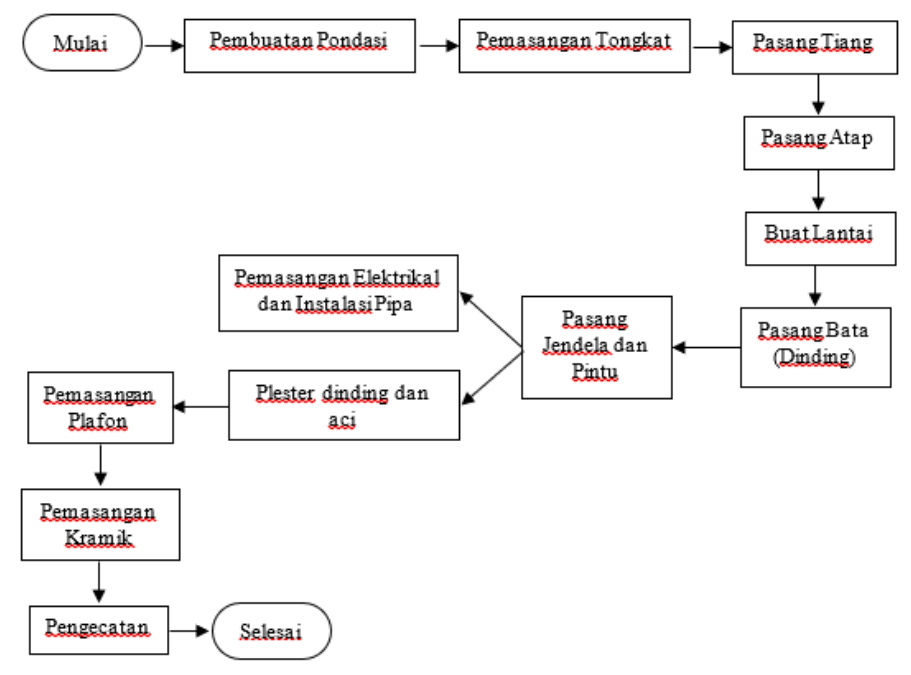

Gambar 2. Proses Pembuatan Rumah Tipe 36 


\section{B. Aliran Proses Produksi Rumah Tipe 36}

1) Pemasangan Pondasi

Pemasangan pondasi pada rumah berupa pemasangan galam sebanyak 184 buah. Pada proses pemasangan pondasi, operator yang bekerja sebanyak 5 orang dengan proses pemasangan konvensional yaitu menggunakan tenaga manusia untuk pemasangan galam. Waktu penyelesaian dalam pamasangan gala mini selama 3 Hari.

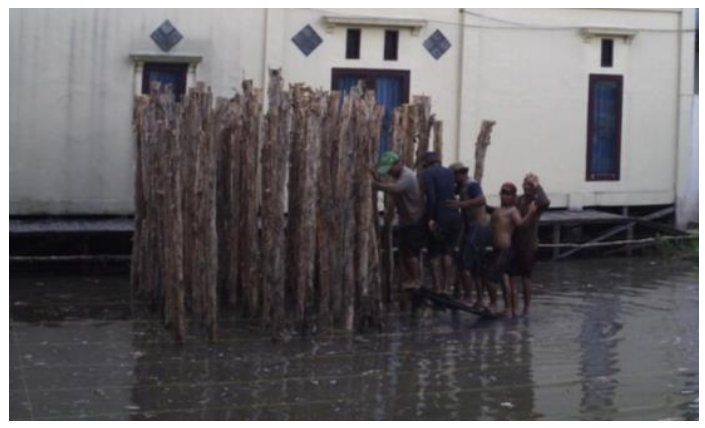

Gambar 3. Pemasangan Cerucuk Dalam

2) Pemasangan Tongkat

Perumahan Griya Anisah Permai menggunakan ulin $10 \mathrm{~cm} \times 10 \mathrm{~cm}$ untuk tongkat rumah, dengan banyaknya ulin yang digunakan sebanyak 46 buah, selain pemasangan tongkat, sepatu/lapik dan sunduk juga dipasang untuk memperkuat pondasi dari rumah tersebut. Pada pemasangan tongkat ini operator/tukang yang bekerja sebanyak 5 orang sama dengan proses pemasangan pondasi. Proses pemasangan pondasi sampai dengan pemasangan tongkat memerlukan waktu selama 3 Hari kerja.

3) Pemasangan rangka rumah

Pemasangan rangka rumah dimulai dari pemasangan tiang sampai kuda-kuda atap, serta sampai pemasangan atap. Pemasangan rangka rumah ini menggunakan 3 operator/tukang dengan waktu selesai selama 4 hari kerja. Dengan menggunakan tiang ulin sebanyak 20 buah ukuran $6 \mathrm{~cm} \times 8 \mathrm{~cm}$ Panjang 3 meter.

4) Pengecoran Lantai dan Dinding

Pengecoran Lantai Rumah menggunakan semen dan kayu sebagai wadah cetakan. Semen yang digunakan sebanyak 50 buah serta pasir sebanyak $4 \mathrm{~m}^{3}$. Sedangkan kayu yang digunakan sebagai wadah cetakan digunakan sebanyak 670 buah. Sedangkan untuk pemasangan dinding untuk rumah menggunakan batu bata 6000 buah batu bata. Proses pembuatan ini dilakukan selama 18 hari. Jumlah operator yang mengerjakan proses pengecoran lantai dan dinding sebanyak 4 Orang.

5) Pemasangan Elektrikal dan Pemasangan Plafon

Proses pemasangan elektrikal menggunakan 1 orang operator dan hanya memerlukan waktu selama 1 hari, sedangkan pemasangan plafon menggunakan 2 orang operator/tukang dengan waktu penyelesaian selama 3 Hari.
6) Pemasangan Keramik

Pemasangan keramik dilakukan beriringan dengan pemasangan plafon. Jumlah operator yang digunakan sebanyak 3 orang. Waktu penyelesaian pada proses ini selama 3 Hari.

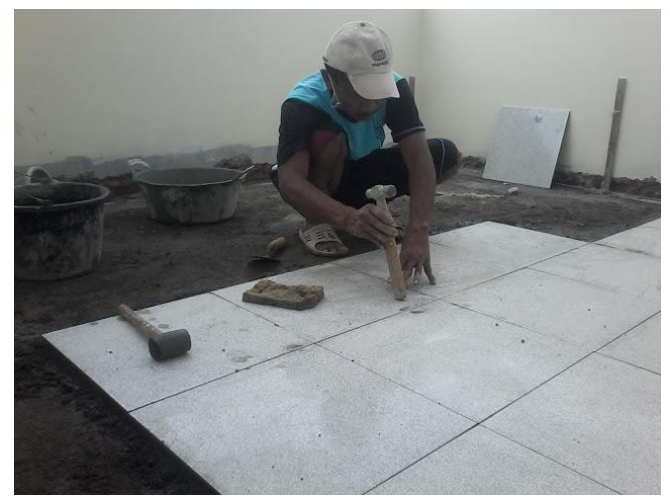

Gambar 4. Pemasangan Keramik

7) Pengecatan Rumah

Waktu penyelesaian pengecatan ini selama 3 hari dengan menggunakan operator/tukang sebanyak 2 orang.

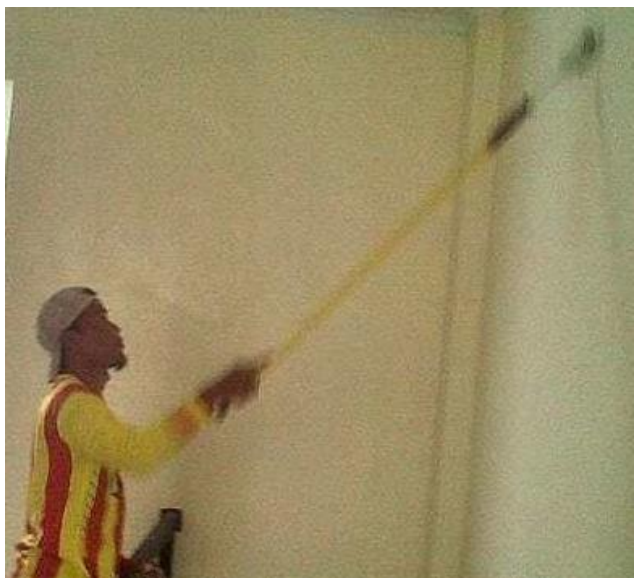

Gambar 5. Pengecatan Rumah

\section{Aktivitas Produksi}

Aktivitas produksi menjelaskan langkah-langkah yg dilakukan dalam pelaksanaan proses produksi. Berikut adalah aktivitas dari proses produksi pembuatan rumah tipe 36 :

Tabel 1. Aktivitas Produksi

\begin{tabular}{|c|c|l|}
\hline Proses & No & \multicolumn{1}{c|}{ Aktivitas } \\
\hline \multirow{4}{*}{$\begin{array}{c}\text { Pemasangan } \\
\text { Pondasi }\end{array}$} & 1 & Membawa Galam panjang 3 m \\
\cline { 2 - 3 } & 2 & Memasang Galam \\
\cline { 2 - 3 } & 3 & Mengambil Tongkat Ulin \\
\cline { 2 - 3 } & 4 & Memasang Lapik/Sepatu \\
\cline { 2 - 3 } & 5 & Memasang Sunduk \\
\hline \multirow{2}{*}{$\begin{array}{c}\text { Pemasangan } \\
\text { Rangka }\end{array}$} & 6 & $\begin{array}{l}\text { Mengambil Kayu Ulin Uk 5cm x } \\
\text { 10cm }\end{array}$ \\
\cline { 2 - 3 } & 7 & Memasang Slop \\
\hline
\end{tabular}




\begin{tabular}{|c|c|c|}
\hline & 8 & $\begin{array}{l}\text { Mengambil Kayu Ulin Uk 5cm x } \\
7 \mathrm{~cm}\end{array}$ \\
\hline & 9 & Memasang Gelagar \\
\hline & 10 & $\begin{array}{l}\text { Mengambil bahan Papan untuk } \\
\text { wadah cetakan lantai }\end{array}$ \\
\hline & 11 & Memasang papan \\
\hline & 12 & Mengambil kayu ulin \\
\hline & 13 & Memasang Tiang \\
\hline & 14 & Mengambil Atap \\
\hline & 15 & Memasang Atap \\
\hline \multirow{6}{*}{$\begin{array}{l}\text { Pembuatan } \\
\text { Dinding dan } \\
\text { Lantai Cor }\end{array}$} & 16 & Mengambil Semen, Pasir dan Batu \\
\hline & 17 & $\begin{array}{l}\text { Mengecor Lantai dan Kamar Mandi } \\
\text { serta pemasangan kloset }\end{array}$ \\
\hline & 18 & Mengambil Batu Bata \\
\hline & 19 & Memasang Dinding \\
\hline & 20 & Memasang Kusen Pintu dan Jendela \\
\hline & 21 & Memplaster Dinding \\
\hline \multirow{5}{*}{$\begin{array}{c}\text { Pemasangan } \\
\text { Elektrikal } \\
\text { Dan Instalasi Pipa }\end{array}$} & 22 & Mengambil Bahan Baku Elektrikal \\
\hline & 23 & Membuat jalur jaringan di dinding \\
\hline & 24 & $\begin{array}{l}\text { Memasang Saklar lampu dan Stop } \\
\text { Kontak }\end{array}$ \\
\hline & 25 & Mengambil Semen Putih \\
\hline & 26 & $\begin{array}{l}\text { Mencor dinding yang telah dilubangi } \\
\text { bekas jaringan }\end{array}$ \\
\hline \multirow{5}{*}{$\begin{array}{l}\text { Pemasangan } \\
\text { Plafon }\end{array}$} & 27 & Mengambil Bahan Kayu \\
\hline & 28 & Memasang rangka plafon \\
\hline & 29 & Mengambil Kalsiboard \\
\hline & 30 & Memasang Plafon \\
\hline & 31 & Memplamir plafon \\
\hline \multirow{4}{*}{$\begin{array}{l}\text { Pemasangan } \\
\text { Keramik }\end{array}$} & 32 & Mengambil Bahan Keramik \\
\hline & 33 & Mengambil Semen \\
\hline & 34 & Memasang Keramik Lantai \\
\hline & 35 & Memasang Keramik Kamar mandi \\
\hline \multirow{6}{*}{$\begin{array}{l}\text { Pengecatan dan } \\
\text { Finishing }\end{array}$} & 36 & Mengambil bahan cat dan plamir \\
\hline & 37 & Plamir dinding dalam \\
\hline & 38 & Plamir dinding luar \\
\hline & 39 & Pengecatan dinding dalam \\
\hline & 40 & Pengecatan dinding luar \\
\hline & 41 & Pengecekan finishing \\
\hline
\end{tabular}

\section{Operator Proses Produksi}

Berikut adalah jumlah operator dan cycle time pada masing-masing proses produksi rumah tipe 36 .

Tabel 2. Operator Proses Produksi

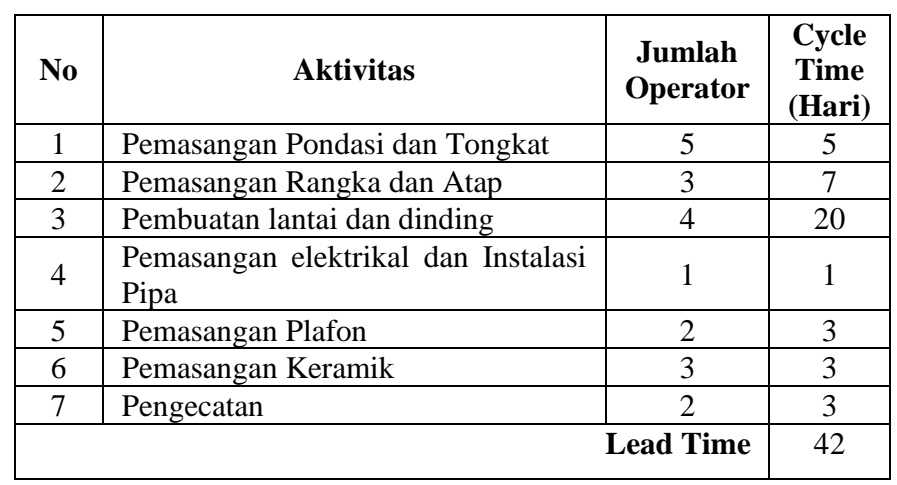

Dari hasil pengamatan di lapangan dapat diketahui bahwa untuk menyelesaikan satu buah rumah dengan tipe 36 diperlukan Lead Time selama 42 hari kerja.

\section{E. Current State Value Stream Mapping}

Current State Value Stream Mapping merupakan diagram yang menunjukkan arus material dan informasi aktual dan juga menggambarkannya bagaimana proses sebenarnya beroperasi. Berikut Current State Value Stream Mapping berdasarkan pengamatan dan brainstorming yang telah dilakukan.

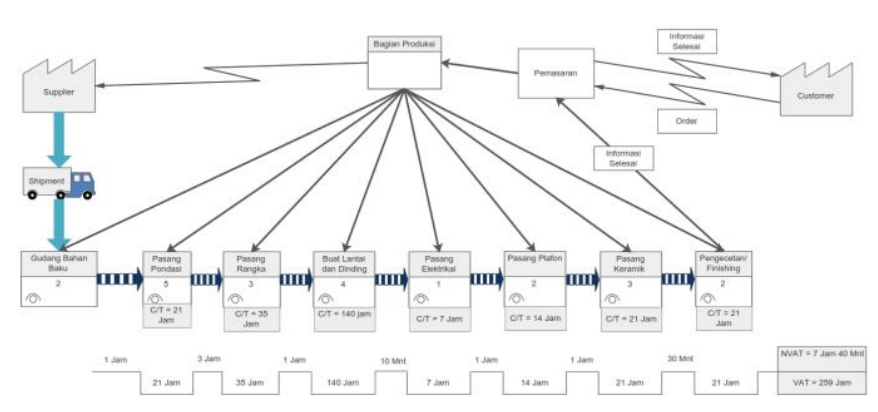

Gambar 6. Current State Value Stream Mapping

\section{F. Identifikasi Waste}

Dalam suatu proses produksi pastinya akan selalu terdapat waste atau pemborosan. Berdasarkan pengamatan dan pengambilan data di lapangan berupa wawancara serta brainstorming dengan pihak terkait yaitu bagian produksi diperoleh beberapa waste atau pemborosan yang memang menjadi kendala atau masalah di tempat tersebut.

1. Persediaan Bahan Baku (Inventory)

Pemborosan pada bidang ini sangat berpengaruh terhadap penyelesaian sebuah rumah, dikarenakan jika bahan baku untuk membuat rumah tidak ada maka proses produksi akan terhenti. Berdasarkan hasil brainstorming yang dilakukan, penyebab terjadinya lambatnya persediaan bahan baku ini dikarenakan bahan baku yang kosong dari supplier, contoh adalah kayu ulin yang sangat susah didapatkan dan harganya semakin mahal jika ada kekosongan. Kekosongan yang terjadi dikarenakan banyaknya pelaku usaha dibidang perumahan yang juga memerlukan bahan baku ini sehingga permintaan terhadap kayu ulin semakin banyak sementara bahan yang tersedia terbatas. Selain kayu ulin, bahan baku untuk pondasi seperti cerucuk galam juga kadang-kadang susah dicari sehingga proses produksi menjadi terhambat ketika bahan-bahan baku tersebut tidak ada.

2. Menunggu (Waiting)

Dalam proses pembuatan sebuah rumah diperlukan operator/tukang yang harus ready setiap ada pekerjaan yang harus dikerjakannya. Permasalah yang terjadi jika permintaan order dari customer banyak, misalnya harus membangun 10 buah rumah, sedangkan sumber daya manusia atau tukangnya tidak cukup maka pembuatan rumah tersebut akan terhenti untuk menyelesaikan rumah satu persatu. Alternative yang sering dilakukan oleh pihak pengembang atau bagian produksi adalah dengan merekrut 
tukang tambahan untuk menyelesaikan 10 rumah tersebut sekaligus. Tetapi untuk mencari tukang tambahan tidak semudah yang diharapkan karena kualitas dari tukang tersebut belum tentu bagus dari pada tukang yang sudah biasa bekerja untuk perusahaan tersebut. Sehingga hal tersebut menjadi sedikit kendala jika hasil pekerjaan dari tukang tambahan tersebut tidak bagus. Selain membuang waktu juga membuang biaya bahan baku. Dalam current Value Stream Mapping diketahui Lead Time selama 42 Hari, tetapi berdasarkan informasi dari bagian produksi ternyata lead time yang optimal untuk menyelesaikan rumah type 36 hanya memerlukan 35 Hari Kerja. Sehingga ada perbedaa 7 Hari kerja dari keadaan sekarang dengan standar waktu yang ditetapkan oleh bagian produksi.

3. Gerakan Tidak Perlu (Unnecessary Motion)

Belum adanya standar produksi pada masing-masing bidang menyebabkan banyaknya Gerakan yang tidak perlu dalam hal proses produksi pada setiap bagian. Apalagi masingmasing tukang memiliki pengalaman serta kualitas yang berbeda-beda menyebabkan susahnya membuat suatu standar yang baku untuk membuat sebuah rumah. Hal ini yang perlu dipikirkan oleh pihak pengembang, bagaimana melakukan pelatihan kepada tukang tersebut agar memiliki kemampuan atau keterampilan yang lebih bagus, sehingga Gerakan-gerakan yang tidak perlu dapat dikurangi bahkan dapat dihilangkan

\section{G. Process Activity Mapping}

Tool ini bertujuan untuk menghilangkan aktivitas yang tidak diperlukan, mengidentifikasi apakah suatu proses dapat lebih diefisienkan lagi, serta mencari perbaikan yang dapat mengurangi pemborosan [10].

Tabel 3. Process Activity Mapping

\begin{tabular}{|c|c|c|c|c|c|c|c|c|}
\hline \multirow{2}{*}{ No } & \multirow{2}{*}{ Proses } & \multirow{2}{*}{$\begin{array}{l}\text { Waktu } \\
\text { (Jam) }\end{array}$} & \multicolumn{5}{|c|}{ Aktivitas } & \multirow[t]{2}{*}{ Ket } \\
\hline & & & $\mathbf{O}$ & $\mathbf{T}$ & I & $\mathbf{S}$ & D & \\
\hline 1 & $\begin{array}{l}\text { Membawa Galam panjang } \\
3 \mathrm{~m}\end{array}$ & 0,30 & & $\mathrm{~T}$ & & & & NNVA \\
\hline 2 & Memasang Galam & 14 & $\mathrm{O}$ & & & & & VA \\
\hline 3 & Mengambil Tongkat Ulin & 0,30 & & $\mathrm{~T}$ & & & & NNVA \\
\hline 4 & Memasang Lapik/Sepatu & 3,5 & $\mathrm{O}$ & & & & & VA \\
\hline 5 & Memasang Sunduk & 3,5 & $\mathrm{O}$ & & & & & VA \\
\hline 6 & $\begin{array}{l}\text { Mengambil Kayu Ulin Uk } \\
5 \mathrm{~cm} \times 10 \mathrm{~cm}\end{array}$ & 0,15 & & $\mathrm{~T}$ & & & & NNVA \\
\hline 7 & Memasang Slop & 7 & $\mathrm{O}$ & & & & & VA \\
\hline 8 & $\begin{array}{l}\text { Mengambil Kayu Ulin Uk } \\
5 \mathrm{~cm} \times 7 \mathrm{~cm}\end{array}$ & 0,15 & & $\mathrm{~T}$ & & & & NNVA \\
\hline 9 & Memasang Gelagar & 7 & $\mathrm{O}$ & & & & & VA \\
\hline 10 & $\begin{array}{l}\text { Mengambil bahan Papan } \\
\text { untuk lantai }\end{array}$ & 1,5 & & $\mathrm{~T}$ & & & & NNVA \\
\hline 11 & Memasang papan & 7 & $\mathrm{O}$ & & & & & VA \\
\hline 12 & Mengambil kayu ulin & 0,15 & & $\mathrm{~T}$ & & & & NNVA \\
\hline 13 & Memasang Tiang & 7 & $\mathrm{O}$ & & & & & VA \\
\hline 14 & Mengambil Atap & 0,45 & & $\mathrm{~T}$ & & & & NNVA \\
\hline 15 & Memasang Atap & 7 & $\mathrm{O}$ & & & & & VA \\
\hline 16 & $\begin{array}{l}\text { Mengambil Semen, Pasir } \\
\text { dan Batu }\end{array}$ & 0,30 & & $\mathrm{~T}$ & & & & NNVA \\
\hline
\end{tabular}

\begin{tabular}{|c|l|c|c|c|c|c|c|c|}
\hline \multirow{2}{*}{ No } & \multirow{2}{*}{ Proses } & \multirow{2}{*}{$\begin{array}{l}\text { Waktu } \\
(\text { Jam })\end{array}$} & \multicolumn{5}{|c|}{ Aktivitas } & Ket \\
\cline { 5 - 8 } & & 35 & O & T & I & S & D & \\
\hline 17 & $\begin{array}{l}\text { Mengecor Lantai dan } \\
\text { Masang Kloset }\end{array}$ & & & & & VA \\
\hline 19 & Mengambil Batu Bata & 0,30 & & T & & & & NNVA \\
\hline 20 & $\begin{array}{l}\text { Memasang Dinding } \\
\text { Memasang Kusen Pintu dan }\end{array}$ & 56 & O & & & & & VA \\
\hline
\end{tabular}

\begin{tabular}{|c|l|c|c|c|c|c|c|c|}
\hline 21 & Memplaster Dinding & 14 & $\mathrm{O}$ & & & & & VA \\
\hline 22 & $\begin{array}{l}\text { Mengambil Bahan Baku } \\
\text { Elektrikal }\end{array}$ & 0,05 & & $\mathrm{~T}$ & & & & NNVA \\
\hline 23 & $\begin{array}{l}\text { Membuat jalur jaringan di } \\
\text { dinding }\end{array}$ & 2 & $\mathrm{O}$ & & & & & VA \\
\hline 24 & $\begin{array}{l}\text { Memasang Saklar lampu } \\
\text { dan Stop Kontak }\end{array}$ & 4 & $\mathrm{O}$ & & & & & VA \\
\hline 25 & Mengambil Semen Putih & 0,05 & & $\mathrm{~T}$ & & & & NVA \\
\hline 26 & $\begin{array}{l}\text { Mencor dinding yang telah } \\
\text { dilubangi bekas jaringan }\end{array}$ & 1 & $\mathrm{O}$ & & & & & VA \\
\hline 27 & Mengambil Bahan Kayu & 0,30 & & $\mathrm{~T}$ & & & & NNVA \\
\hline 28 & Memasang rangka plafon & 7 & $\mathrm{O}$ & & & & & VA \\
\hline 29 & Mengambil Kalsiboard & 0,30 & & $\mathrm{~T}$ & & & & NVA \\
\hline 30 & Memasang Plafon & 5 & $\mathrm{O}$ & & & & & VA \\
\hline 31 & Memplamir plafon & 2 & $\mathrm{O}$ & & & & & VA \\
\hline 32 & Mengambil Bahan Keramik & 0,30 & & $\mathrm{~T}$ & & & & NNVA \\
\hline 33 & Mengambil Semen & 0,20 & & $\mathrm{~T}$ & & & & NVA \\
\hline 34 & Memasang Keramik Lantai & 14 & $\mathrm{O}$ & & & & & VA \\
\hline 35 & $\begin{array}{l}\text { Memasang Keramik Kamar } \\
\text { mandi }\end{array}$ & 7 & $\mathrm{O}$ & & & & & VA \\
\hline 36 & $\begin{array}{l}\text { Mengambil bahan cat dan } \\
\text { plamir }\end{array}$ & 0,30 & & $\mathrm{~T}$ & & & & NVA \\
\hline 37 & Plamir dinding dalam & 4 & $\mathrm{O}$ & & & & & VA \\
\hline 38 & Plamir dinding luar & 5 & $\mathrm{O}$ & & & & & VA \\
\hline 39 & Pengecatan dinding dalam & 5 & $\mathrm{O}$ & & & & & VA \\
\hline 40 & Pengecatan dinding luar & 7 & $\mathrm{O}$ & & & & & VA \\
\hline 41 & Pengecekan finishing & 1 & & & $\mathrm{I}$ & & & NNVA \\
\hline
\end{tabular}

\section{H. Analisis Pengurangan Waste/Pemborosan}

Dengan mengurangi waste pada jalur produksi maka akan berdampak pada peningkatan produktivitas produksi. Untuk itu perlu adanya kolaborasi antara pihak produksi dengan para operator/tukang di lapangan, dengan bersama-sama melakukan perbaikan bukan hanya dari standar pengerjaan atau pun mengurangi kegiatan-kegiatan yang tidak perlu, maka akan menciptakan suatu ekosistem kerja yang produktif, efektif dan efisien.

1. Persediaan Bahan Baku

Berdasarkan hasil Analisa yang telah dilakukan untuk mengurangi permasalah mengenai tidak tersedianya bahan baku khususnya kayu ulin yang mana banyak digunakan dalam membangun rumah tipe 36 ini, maka perlu adanya kerjasama yang lebih bagus dengan menjadikan supplier kayu ulir untuk menjadi mitra, jadi bukan hanya sebagai pembeli dan penjual yang otomatis jika ada pihak lain yang menginginkan kayu ulin tersebut maka akan dilepas ke pihak tersebut. Dengan diajaknya para supplier kayu ulin sebagai mitra, maka pihak pengembang perumahan Griya Anisah Permai akan menjadi prioritas untuk kesediaan bahan baku khususnya kayu ulin.

2. Menunggu (waiting)

Hal ini sering terjadi karena kurang koordinasinya pihak marketing/pemasaran dengan lapangan, di mana miskomunikasi ini mengakibatkan terjadinya waiting list dalam hal pembangunan rumah. Menurut peneliti sebaiknya pihak marketing melakukan komunikasi terhadap pihak produksi di lapangan, berapa tukang atau tenaga kerja yang siap untuk membangun rumah. Setelah mengetahui kesiapan jumlah tenaga kerja/tukang di lapangan. Maka pihak produksi bisa melakukan planning dengan menentukan jumlah rumah yang bisa dibuat. Setelah perencanaan dibuat maka pihak marketing langsung bisa menginformasikan kepada konsumen dengan memberikan waiting list, sehingga mereka tahu giliran dan kapan rumah mereka akan dibangun. Hal ini akan mengurangi keluhan dari konsumen yang sering mengeluh karena lamanya 
proses pembangunan rumah. Padahal yang terjadi adalah kurangnya tenaga kerja.

3. Gerakan Tidak Perlu (Unnecessary Motion)

Karena belum adanya standar proses produksi pada tiap-tiap proses, ada baiknya pihak produksi memberikan target selesai kepada operator/tukang. Sehingga para tukang tidak banyak membuat Gerakan yang tidak perlu sehingga membuat penyelesaian pembuatan rumah semakin lama. Di mana diketahui bahwa pembangunan rumah dari awal sampai selesai memerlukan 40 hari kerja atau 259 Jam, sedangkan dari perhitungan yang sudah direncanakan oleh pihak produksi bahwa untuk menyelesaikan pembangunan rumah tipe 36 dari awal sampai selesai hanya membutuhkan 35 hari kerja atau $245 \mathrm{Jam}$, yang mana selisih dari proses penyelesaian dari pengamatan langsung dengan perencanaan adalah 14 jam atau sekitar 2 hari.

\section{Perbaikan Future State Value Stream Mapping}

Usulan perbaikan dilakukan untuk mengurangi atau membuang waktu pada setiap aktivitas yang tidak bernilai tambah (Non Value Added). Proses yang coba dikurangi adalah proses transportasi pengantaran bahan baku dari Gudang ke lokasi kerja. Sebaiknya bahan-bahan seperti galam, kayu ulin dan bahan lain yang aman terhadap basah langsung dari supplier ke lokasi kerja, sehingga mengurangi transportasi yang tidak penting pada saat proses produksi.

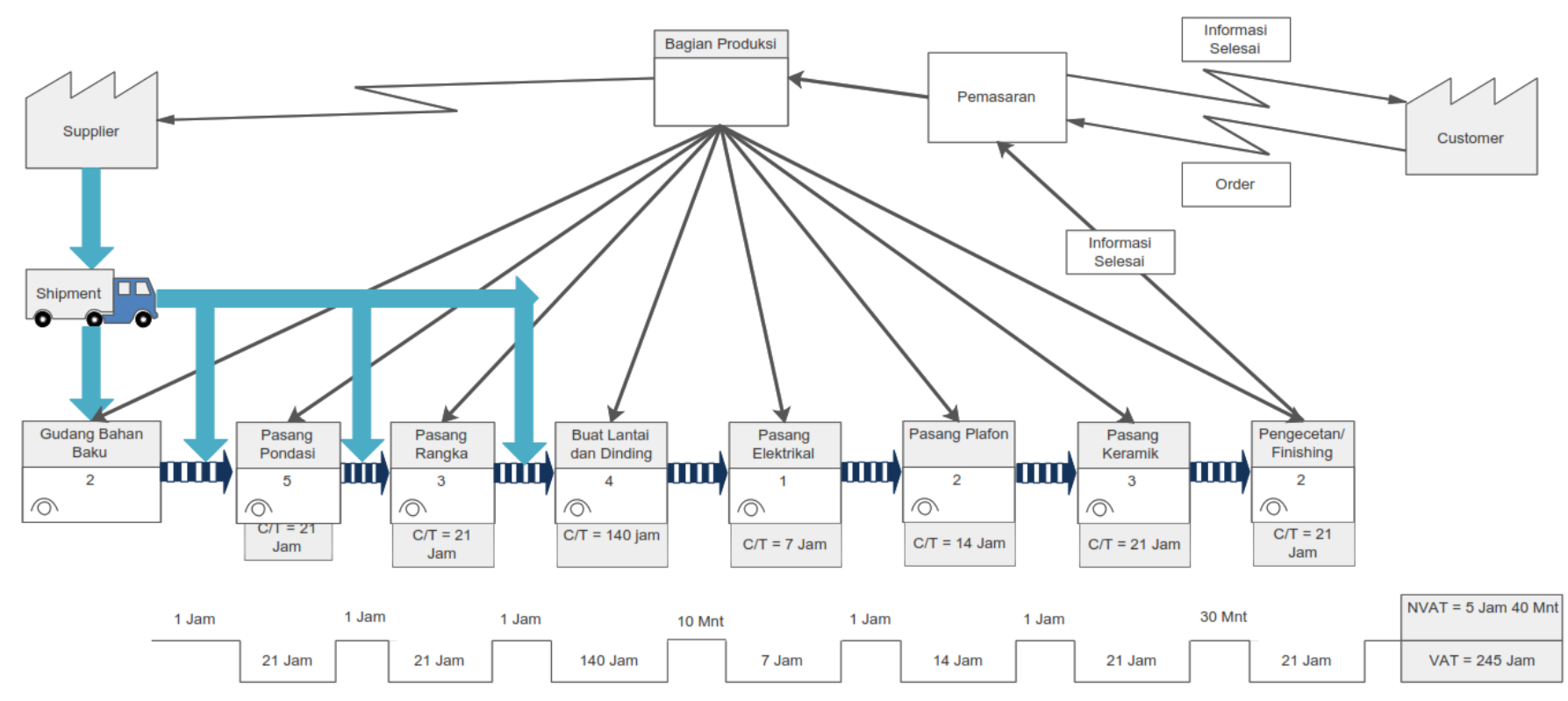

Gambar 7. Future State Value Stream Mapping

\section{KESIMPULAN}

Dari hasil analisis dapat dipat disimpulkan sebagai berikut :

1. Waste pada persediaan bahan baku dapat diatasi dengan mengajak supplier sebagai mitra kerja bukan hanya sebagai pembeli dan penjual, untuk mengurangi waste pada waiting dapat diatasi dengan melakukan komunikasi antara pihak marketing dengan pihak produksi agar lebih optimal sedangkan pada Gerakan yang tidak perlu sebaiknya dibuat standar tetap pada tiap-tiap proses.

2. Pengurangan transportasi akan meningkatkan produktivitas kerja, dengan mengantar bahan baku langsung dari supplier ke lokasi kerja, maka akan mempersingkat waktu transportasi dari Gudang ke lokasi kerja.

\section{SARAN}

Saran kepada pihak perusahaan agar bisa membuat sebuat aturan serta target penyelesaian projek dengan membuat menerapkan manajemen proyek agar proses produksi sesuai dengan perencanaan awal.

\section{DAFTAR PUSTAKA}

[1] H. Herawati and D. Mulyani, "PENGARUH KUALITAS BAHAN BAKU DAN PROSES PRODUKSI TERHADAP KUALITAS PRODUK PADA UD. TAHU ROSYDI PUSPAN MARON PROBOLINGGO," in Prosiding Seminar Nasional, Gedung Pascasarjana FEB UNEJ, 2016.

[2] A. Mutiasari and A. J. Pratama, "PERANCANGAN VALUE STREAM MAPPING PROSES PRODUKSI MAINAN KAYU PADA CV. MK," in Seminar Nasional Teknologi dan Informatika (SNATIF), Kampus Universitas Muria Kudus, 2017.

[3] F. Rossianti, M. Iqbal, and A. Suryabrata, "USULAN PERBAIKAN UNTUK MENGURANGI LEAD TIME PADA PLASTIC INJECTION MENGGUNAKAN METODE LEAN SIX SIGMA DI PT X,” $J$. Rekayasa Sist. Dan Ind., vol. 1, no. 1, p. 7, 2014.

[4] M. Majid, "IDENTIFIKASI DAN PENGURANGAN WASTE PADA PROSES PRODUKSI MINUMAN HERBAL INSTAN MENGGUNAKAN VALUESTREAM MAPPING," Skripsi, Universitas Islam Indonesia, Yogyakarta, 2018. 
[5] A. Jakfar and W. E. Setiawan, "PENGURANGAN WASTE MENGGUNAKAN PENDEKATAN LEAN MANUFACTURING," $J$. Ilm. Tek. Ind., vol. 13, no. 1, p. 11, 2014.

[6] T. Prayogo and T. Octavia, "Identifikasi Waste dengan Menggunakan Value Stream Mapping di Gudang PT. XYZ,' J. Titra, vol. 1, no. 2, p. 8, 2013.

[7] G. S. Intifada and Witantyo, "Minimasi waste (pemborosan) menggunakan value stream analysis tool untuk meningkatkan efisiensi waktu produksi (Studi kasus: PT Barata Indonesia)," J. Tek. ITS POMITS Publ. Online ITS, vol. 1, no. 1, p. 6, 2012.

[8] M. S. A. Khannan and H. Haryono, "Analisis Penerapan Lean Manufacturing untuk Menghilangkan Pemborosan di Lini Produksi PT Adi Satria Abadi," J. Rekayasa Sist. Ind., vol. 4, no. 1, p. 47, Oct. 2017, doi: 10.26593/jrsi.v4i1.1383.47-54.
[9] A. Tiwari and D. A. Manoria, "Value stream mapping based Lean Production System," Int. J. Res. Aeronaut. Mecahinal Eng., vol. 4, no. 8, pp. 10-24, 2016.

[10] A. Misbah, P. Pratikto, and D. Widhiyanuriyawan, "UPAYA MEMINIMALKAN NON VALUE ADDED ACTIVITIES PRODUK MEBEL DENGAN PENERAPAN METODE LEAN MANUFACTURING," J. Eng. Manag. Industial Syst., vol. 3, no. 1, Mar. 2015, doi: 10.21776/ub.jemis.2015.003.01.8.

[11] D. A. Hardianza and I. Vanany, "IMPLEMENTASI LEAN MANUFACTURING DENGAN METODE VALUE STREAM MAPPING PADA PT. X," Tesis, Institut Teknologi Sepuluh Nopember, Surabaya, 2016. 